greater tendency to oscillate at more than one frequency. As a result $\eta_{\mathrm{el}}$ could be lower than for a single frequency and the window must be matched over a large bandwidth which complicates its design especially at high power. The growth of all the unstable EM waves and their subsequent non-linear evolution has been studied numerically by $A$. Bondeson et al. ${ }^{7}$ ). Starting from the noise level, typically a self-consistent time evolution of around 20 modes, separated in frequency by $c / 2 d$, is followed. The calculation is self-consistent in the sense that the oscillating current $j(\omega)$ which creates the EM field results from the interaction of the electron beam with the EM field itself. Single mode operation could be achieved however, with a suitable profile of $B_{0}$ and mode selectivity should be improved.

The potentialities of a quasi-optical gyrotron are not yet fully assessed. Results from the Naval Research Laboratories presented at a recent meeting ${ }^{8}$ ) have provided confirmation of the numerical predictions of the code of Bondeson et al. in regard to both the frequency spectrum and its temporal evolution. However, the measured total efficiency was low $\left(\eta_{\text {tot }} \cong 6 \%\right.$ ) and this has been attributed to the low perpendicular energy of the beam and the large loss in the coupling efficiency ( $\eta_{\text {out }} \cong 53 \%$ ). Further experiments are now in preparation in the US as well as in our own laboratory.

The performance of present gyrotrons are summarized and compared to other electron tubes in Fig. 4. We have restricted ourselves in this survey to devices which use weakly relativistic electron beams (beam energy $E_{\mathrm{b}}<100 \mathrm{keV}$ ) although gyrotrons with $E_{\mathrm{b}}>200 \mathrm{keV}$ have been tested and give an output power in the range of $10 \mathrm{MW}-1 \mathrm{GW}$ in the frequency range of $8 \mathrm{GHz}$ to 120 $\mathrm{GHz}$. In Fig. 4 we have distinguished between short pulse devices (pulse length $<5 \mathrm{~ms}$ ) and longer pulse tubes (pulse length $>5 \mathrm{~ms}$ ) based on the published results. It is worth noting that many of the short pulse gyrotrons have $\mathrm{CW}$ features but due to the limitation in the experimental facilities, the tests have only been run on short pulses. Fig. 4 clearly shows that gyrotrons can exceed the power limitation of conventional tubes at high frequency ( $>10 \mathrm{GHz}$ ).

While describing the important issues related to the two concepts presently used in the design of gyrotrons, we have limited ourselves to oscillators only. It is worth noting that amplifiers based on the electron cyclotron maser instability have also been designed: multi-cavities gyroklystrons, gyrotravelling wave amplifiers are the counterparts of the well-known existing electron tubes.

\section{REFERENCES}

1. Riviere A.C., Int. J. Electronics 61 (1986) 693.

2. Granatstein V.L., Vitello P., Chu K.R., Ko K., Latham P.E., Lawson W., Striffler C.D. and Drobot A., IEEE Trans. Nuclear Sci. NS32 (1985) 2957.

3. See for example Flyagin V.A., Gapanov A.V., Petelin M.I. and Yulpatov V.K., IEEE Trans. Microwave Theory Tech. MIT25 (1977) 514.

4. Schneider J., Phys. Rev. Lett. 2 (1959) 504.

5. Kreischer K. and Temkin R.J., Plasma Fusion Center, MIT, Report PFC/JA-87-15 (April 1987).

6. Mathews H.G., Alberti S., Muggli P., Perrenoud A. and Tran M.Q., IEDM Tech. Digest 86 (1986) 805.

7. Bondeson A., Manheimer W. and Ott E., Infrared and Millimeter Waves, Ed. K.J. Button (Academic Press) 9309.

8. Read M.E., Tran M.Q., Mc Adoo J., Hargreaves T., Barsanti M., Lee R. and Manheimer W.M., 11th Int. Conference on Infrared and Millimeter Waves, 1986, Pisa.

\title{
Joint Prizes in Physics 1987
}

The European Physical Society is exceptional in awarding only one prize for physics per year (the Hewlett-Packard Europhysics Prize); the majority of our member organizations have a regular series. Often these commemorate the work of a famous physicist, and have been created to perpetuate the name of an illustrious past member. The total number awarded each year in Europe is difficult to estimate, as some receive wide publicity, at least in the specialist domain concerned, others are known only locally. The figure is certainly many tens.

It would clearly be impossible for Europhysics News to give even a brief review of the reasons behind all these and the careers of those who have been honoured, yet prizes do represent a real comment on recent key research as well as defining who and where this research was done. This is particularly true when the prize awarded is international. The Nobel Prize has for many years been regarded as the ultimate accolade, but there are other prestigious international prizes in physics, notably in Europe the joint paired prizes of the Deutsche Physi- kalische Gesellschaft, the Société Francaise de Physique, and The Institute of Physics of the UK.

These are as follows, listed in the order in which they made their appearance: the HOLWECK prize which was instituted in 1945 by the French and British physical societies; the MAX BORN prize instituted in 1972 by the British and German physical societies, and finally the GENTNER-KASTLER prize instituted by the German and French physical societies, in 1985. The first awards were respectively presented in 1946, 1973 and 1986. The list of recipients today counts 43 names for the Holweck prize, 15 names for the Max Born prize and two names for the Gentner-Kastler prize.

The procedures used for the three awards are almost the same. The Council of one society selects the winner from a list of typically three names presented by the other society, the respective roles of the two societies alternating from year to year. In all three cases, the award consists of a medal and a certificate which is accompanied by a cash prize. The value is $€ 300$ for the Holweck and Max Born prizes and 1000 ECU for the Gentner-Kastler prize, reference to the European Accounting Unit being a sign of its relatively later institution. The key point, however, is that these prizes carry a very high prestige to which the list of past recipients bears clear witness. All three societies consider these joint prizes as among the very few top prizes which they award each year.

Direct links between different physical societies are very important to the harmonious development of physics in Europe. The co-ordination provided by the EPS is strengthened by the numerous and efficient bilateral or multilateral links. Such contacts can take various forms but awarding joint prizes is an efficient way to generate them. This implies regular contacts between officials of two societies which can but naturally develop into other joint studies, activities and ventures. One can only hope that these joint prizes, which are at present limited to the France-Federal Republic of Germany and United Kingdom triangle, will increase in number. However, in order to avoid a prize inflation, this may involve the redefinition of some 
of the present prizes into bilateral ones. Any such move, which would be at the origin of regular contacts between two or more physical societies, can be only highly encouraged.

\section{Award Winners}

We now present the 1987 laureates of the three joint prizes: Edouard Fabre from France for the Holweck prize, Cyril Hilsum from Great Britain, for the Max Born prize and Ernest Wilhelm Otten from Germany, for the Gentner-Kastler prize. We again follow the order of seniority of these prizes which now carry equal prestige.

Edouard Fabre has been leading the laser-plasma group of the Ecole Polytechnique Laboratory in suburban Paris, since 1966. He was among the pioneers in experimenting on the interactions of laser beams with solid targets and eventually to prove the efficiency of plasma heating by this method. Indeed for a long time the efficiency of this heating turned out to be disappointing. It was Fabre's idea that all the effects which conspired at making laser fusion so difficult should highly diminish at short wavelengths. He used non-linear crystals to double and quadruple the radiation frequency. The success this met has strongly influenced the laser fusion programmes all over the world. Fabre has recently achieved his best present results on spherical implosion at short wavelength with a concentration of six beams bringing $140 \mathrm{~J}$ onto the target in $0.5 \mathrm{~ns}$. He has stirred a relatively small group into leadership in the field of laser fusion.

Cyril Hilsum is the director of research at the General Electric Company, Wembley, (GEC) and Visiting Professor at the University of Durham in the field of applied physics and electronics. He began his research career in 1947, studying infrared devices with the Admiralty Research Laboratory and spent most of his
Edouard Fabre receiving at the hands of Godfrey Stafford, President of the British Institute of Physics, the Holweck prize for 1987. Research Establishment, Malvern. He moved to GEC as Chief Scientist in 1983. He has made major contributions in three distinct subject areas: the physics and applications of semi-conductor compounds; infrared and non-linear microwave electronic devices and, more latterly, on visual flat panel displays, based on liquid crystal, electroluminisDelegate to Council of the EPS IOMs from 1978-1981, he is prominent in European solid state science, recognized for his contributions to both the basic physics and the engineering of complex electronic devices.

Ernest Wilhelm Otten is Professor at the Johannes-Gutenberg-Universität, Mainz where he moved from Heidelberg in 1972. His scientific work centres around the investigation of the atomic hyperfine structure for the study of nuclear properties, nuclear moments and nuclear radii. He has thus revived this classical field with many new ideas, combining sophisticated optical measurements on accelerator beams at CERN. In his early work in 1960, he extended optical pumping techniques to radioactive nuclei, using asymmetry in $\beta$ decay as a polarization analyser. He developed the collinear ion beam laser spectroscopy in order to make hyperfine investigations on radium isotopes. His discovery of the odd-even staggering in mercury isotopes, whereby the uneven iso- subsequent career at the Royal Radar cent and electrochromics techniques.

topes appear to have a much larger nuclear radius than the neighbouring even isotopes, is particularly important.

Chairman of the EPS Atomic Physics Division from 1979-1981, he is well known for his important experimental achievements in atomic hyperfine spectroscopy applied to unstable isotopes studied on line at an accelerator, namely the CERN Isolde facility. This is an important contribution at the interface of three different fields in physics.

M. Jacob (CERN)

\section{Next General Meeting}

There is no better occasion for a General Meeting than a General Conference and the Executive Committee proposes that the next such Meeting be held in Amsterdam in conjunction with the 8th General Conference there.

However, there is a technical problem: Rule 12 of the EPS By-Laws states that "the interval between consecutive sessions of the General Meeting should not exceed three years". The recent meeting was held on 12 August and so strictly the next should be held before the middle of August 1990.

The Executive Committee believes that it would be following the spirit of the Rule nevertheless to hold the Meeting during 4-8 September 1990. Any member wishing to lodge a formal objection should do so in writing to the Secretariat before 31 December 1987.

\section{Editor: E.N. Shaw}

Europhysics News is the official journal of the European Physical Society which comprises 29 National Societies, Academies and Group, about 4000 Individual Members and 75 Associate Members. Governing bo dies of EPS are the General Meeting, Council and an elected Executive Committee responsible for detailed policy. EPS promotes the collaboration of physicists throughout Europe, organising and harmonising confe rences and publications, improving physics education, rences and publications, improving physics education, encouraging physics applications, awarding scholarships to sponsored schools in Erice. EPS publishes in addition to Europhys. News, Europhysics Letters lin partnership with national societies), European Journal of Physics (in partnership with The UK Inst. of Phys.) and European Conference Abstracts. Individual Memand European Conference Abstracts. Individual Mem(price to insts.: Sw.Fr. 90.-1a), Europhys. Lett. at Sw.Fr. 70,-1a (insts. 595,-), rebates on many other publications and on conference fees. Annual EPS membership fee for Individual Members belonging to an EPS member society is: SwFr 44.- independent members: Sw.Fr. 132 members of a Collaborating Society: Sw.Fr. 55. -
Editorial Board:

A. Baratoff, F. James, M. Lehmann,

M. Mayor, J. Muller, M. Siegrist

Editorial and Advertising Office at the EPS Secretariat

Address: EUROPEAN PHYSICAL SOCIETY P.O. Box 69 . CH-1213 Petit-Lancy 2

Switzerland

Telephone: Geneva (22) 931130

Telex: 428024 eps ch

Cables: europhys genève

Printed by: Pfirter frères sa CH-1213 Petit-Lancy/Switzerland 